\title{
Method for System Requirements Approval
}

\author{
Lindita Nebiu Hyseni \\ Faculty of Contemporary Sciences and Technologies \\ South East European University \\ Tetovo, Macedonia
}

\author{
Zamir Dika \\ Faculty of Contemporary Sciences and Technologies \\ South East European University \\ Tetovo, Macedonia
}

\begin{abstract}
The requirements approval method is necessary to ensure that the system requirements have been identified in right way and the understanding between the contractor and the client exist. During research conducted is identified that most of the scholars have been working for the requirements definition during the meeting with the client, even they started to initiate the validation by checking whether the requirements captures the needs of client but not the approval of the requirements. Therefore, it is proposed the Joint Approval Requirements (JAR) method based on identified gaps through literature review and work experience. In this paper, this theoretical JAR method has been developed further on, through the presentation of its details about approval of the final version of the functional and nonfunctional requirements document and the integrated conceptual model of the IS. The presented method is ready for the research community in order to implement in different industries to measure the effect of the JAR method in the system requirements.
\end{abstract}

Keywords-Approval method; approve requirements; system requirements; functional and non-functional requirements; joint approval requirements

\section{INTRODUCTION}

The information systems (IS) enable individuals, businesses and society to achieve their goals through information and communication technology components [5]. Considering this, it is very important to review and approve the system requirements by the client in meeting with the contractor. Therefore, is asked the research question, what the scholars worked in this direction? Based on this, the focus is on used methods and techniques during the system analysis and design stage because they impact the successful rate of the information system through the clarification of the incompleteness and inconsistencies that may turn out [1], [2]. During the research conducted is identified that most of the scholars have been working on requirements definition during the meetings with the client, even if they have started to initiate the issue about checking whether the requirements capture the client's need (requirements validations) but not approving the final requirements in these meetings [3], [4]. Consequently, it is proposed the Joint Approval Requirements (JAR) method to be applied in the JAR meetings with the client for reviewing and approving the created functional and non-functional requirements document and the integrated conceptual model based on proposed guides of the Integrated Framework for Conceptual Modeling (IFCMod) [5]. As well, the conceptual modeling plays the crucial role in the success of the information system [7]-[9]. The focus of this paper is to present the details of reason behind the proposed Joint Approval Requirements (JAR) method [1], through a state of the art review for the identification of the research gap, as well as presentation of details of the JAR method. This paper is organized as follows: in Section 2 is state of the art; in the Section 3 are presented identified research gaps; in Section 4 is presented the Joint Approval Requirements (JAR) method; in Section 5 is conclusion and future work; at the end, in Section 6 are presented the references used in this paper.

\section{STATE OF THE ART}

During the research conducted is identified the small number of scholars who have been working for the requirements definition during the meeting with the client, even if they have started to initiate the issue about validation requirements by checking whether the requirements captures the client's need but they do not treated the approval of the requirements. The technique which started to initiate the validation requirements as optional during the session with client is Joint Requirements Planning (JRP) presented by Bentley, L. D., \& Jeffrey, L. (2007). This technique is for problem identification, analysis and system requirements definition during the JRP session. It includes also planning for the JRP session, the way how to conduct the JRP Session, the list of benefits from using this technique, the product of the JRP Session [3].

As well, the Joint Application Development (JAD) technique presented by Dennis, A., Wixom, B. H., \& Roth, R. M. (2012) is used for the requirements definition but in this technique, is not mention the validation or approval of the requirements, even if the client made a decision about which type of requirements seems to be same [4]. This technique allows project team, users, and management to work together to identify requirements for the information system during the JAD Session. It includes the way how selecting participants and location for the JAD session, how to design the JAD session, how to be prepared and conduct the JAD session, and what will be the JAD post-session report. In the following Table 1 is presented comparison of the summary of the JRP and JAD technique.

Considering the identified gaps through literature review, work experience and this comparison presented in Table 1, the proposed Joint Approval Requirements (JAR) method has been developed further on, through the presentation of its details about reviewing and approving the created functional and nonfunctional requirements document and integrated conceptual model based on the IFCMod guides [5], [6]. 
TABLE I. COMPARASION OF THE SUMMARY OF THE JRP AND JAD TECHNIQUE

\begin{tabular}{|c|c|c|}
\hline & Joint Requirements Planning (JRP) & Joint Application Development (JAD) \\
\hline Technique usage & $\begin{array}{l}\text { The JRP technique is used for the problem identification, } \\
\text { analysis and system requirements definition. }\end{array}$ & The JAD technique is used for the requirements definition. \\
\hline Session planning & $\begin{array}{l}\text { Planning for the JRP session contains following steps: } \\
\text { Selecting the location for the JRP session, Selecting JRP } \\
\text { participants (sponsor, facilitator, users and managers, } \\
\text { scribes and IT staff), Preparing the agenda to be followed } \\
\text { during JRP session. }\end{array}$ & $\begin{array}{l}\text { Selecting participants for the JAD session is done by selecting } \\
\text { very best people in business units by providing broad mix of } \\
\text { organizational levels. While the participant which will be JAD } \\
\text { facilitator, will be a consultant external to the organization, } \\
\text { because as the author explains the organization may not have a } \\
\text { regular day-to-day need for JAD expertise. }\end{array}$ \\
\hline Session conducting & $\begin{array}{l}\text { The JRP technique actively involves management and users } \\
\text { in the development of the project; it decreases the time } \\
\text { spending for finding facts in planning and analysis phase; it } \\
\text { confirms requirements and approve prototypes if have, } \\
\text { because prototypes were optional in this technique only for } \\
\text { the functional requirements that needed to be validated }\end{array}$ & $\begin{array}{l}\text { The JAD group meets for several hours, several days, or several } \\
\text { weeks until all of the issues have been discussed and the needed } \\
\text { information is collected. This technique is used in analysis and } \\
\text { design phase. }\end{array}$ \\
\hline Session product & $\begin{array}{l}\text { The product of the JRP session is a formal written } \\
\text { document created usually by JRP facilitator and scribes. } \\
\text { This document is for confirmation of the specifications } \\
\text { agreed on during the JRP session by users and managers. } \\
\text { The content and organization of the specifications depended } \\
\text { on the objectives of JRP session that were, the objective of } \\
\text { the session is not determined. This document is published } \\
\text { immediately following the meeting in order to maintain the } \\
\text { momentum of the JRP session. }\end{array}$ & $\begin{array}{l}\text { The product of the JAD session shall be the post-session report. } \\
\text { This report is prepared and circulated among participants of the } \\
\text { session, it usually takes two or three weeks after JAD session to } \\
\text { be prepared. }\end{array}$ \\
\hline Session Layout & $\begin{array}{l}\text { Selected location shall be the Room Layout in the "U" } \\
\text { shape with additional tables for the IT professionals, other } \\
\text { observers and scribe; It presents which position is placed in } \\
\text { which part of the room; Also, the room layout includes the } \\
\text { dimension of the room and food \& refreshments inside the } \\
\text { meeting room.). } \\
\text { The room layout presents the way of the organization of the } \\
\text { meeting }\end{array}$ & $\begin{array}{l}\text { This technique specifies: The location for the JAD session by } \\
\text { presenting the JAD Meeting Room in "U" shape. It doesn t } \\
\text { present which position is placed in which part of the room; } \\
\text { How to design the JAD session. Most of the JAD sessions are } \\
\text { used to collect information from users, so it is required to } \\
\text { develop set of question before starting the meeting. } \\
\text { The room layout does not present the way of the organization of } \\
\text { the meeting }\end{array}$ \\
\hline
\end{tabular}

\section{JOINT APPROVAL REQUIREMENTS (JAR) METHOD}

The proposed method called Joint Approval Requirements (JAR) used in the JAR meetings with clients allows reviewing and approving the document of the functional requirements and the non-functional requirements (FRs \& NFRs DOC), and the integrated conceptual model (ICM) which are created by using guides of the Integrated Framework for Conceptual Modeling (IFCMod) [5], [6]. In the following are presented two types of JAR meetings including structure and facilitation.

Unit JAR meetings - in the Unit JAR meeting, the participants from the client side shall be: Top Management, Unit Manager, Unit users and IT Team or System Analyst. If it does not have IT Team on the client side, it`s recommended to employ the system analyst for this process. While, the participants from the contractor side shall be: Top Management, Managers and IT Team (System Analyst, System Developer, Database Developer, System Administrator, and System Network Engineer), JAR Scribes which shall be the persons who written the functional and non-functional requirements document (FRs \& NFRs DOC) and modeled the graphical representation of the integrated conceptual model (ICM) and JAR Presenter (The system analyst) who present the FRs \& NFRs DOC and ICM. The number of Unit JAR meetings depending on the number of units on the client side. If the Unit JAR meeting is holding for the information system which shall be developed in-house than the Top Management and IT team shall be in the role of the contractor and the client, whereas the Unit Managers and Unit users shall be in the role of the client. Different from the other position of the IT Team, the system analyst of the institution shall be in the role of the JAR Facilitator, JAR Presenter, and JAR Scriber. In Fig. 1 is presented the Unit JAR Meeting Room Layout and the way of organization.

Final JAR meeting - in the Final JAR meeting, the participants from the client side shall be: Top Management, all Units`Managers, and IT Team or System Analyst. While, the participants from the contractor side shall be: Top Management, Managers and IT Team, JAR Scribes and JAR Presenter. If the Final JAR meeting is holding for the information system which shall be developed in-house than the Top Management and IT team shall be in the role of the contractor and the client, whereas the Unit Managers shall be in the role of the client. Different from the other position of the IT Team, the system analyst of the institution shall be in the role of the contractor who represents JAR Facilitator, JAR Presenter, and JAR Scriber.

In principle, shall be only one Final JAR meeting, but if the number of Units in the client side is too big, then the Final JAR meeting shall be in groups until all units shall be included. Units shall be included in a group based on work dependency on each other. In Fig. 2 is presented the Final JAR Meeting Room Layout and the way of organization. 
The preparation of the Unit and Final JAR meeting shall be done by JAR Facilitator based on the following duties:

Defining the objectives of the JAR meetings by explaining the purpose which shall be the approval of the FRs \& NFRs DOC and ICM after reviewing by the client in JAR meeting with the contractor: If the requirements document and the ICM are for the information system which shall be developed inhouse than the client shall be the Top Management, Unit Managers, Unit Users and IT Team except for system analyst because s/he shall be in the role of the contractor. Also, the Top Management shall be in the role of the contractor if it is needed. Additional, the FRs \& NFRs DOC and ICM shall be provided from a system analyst on the contractor side.

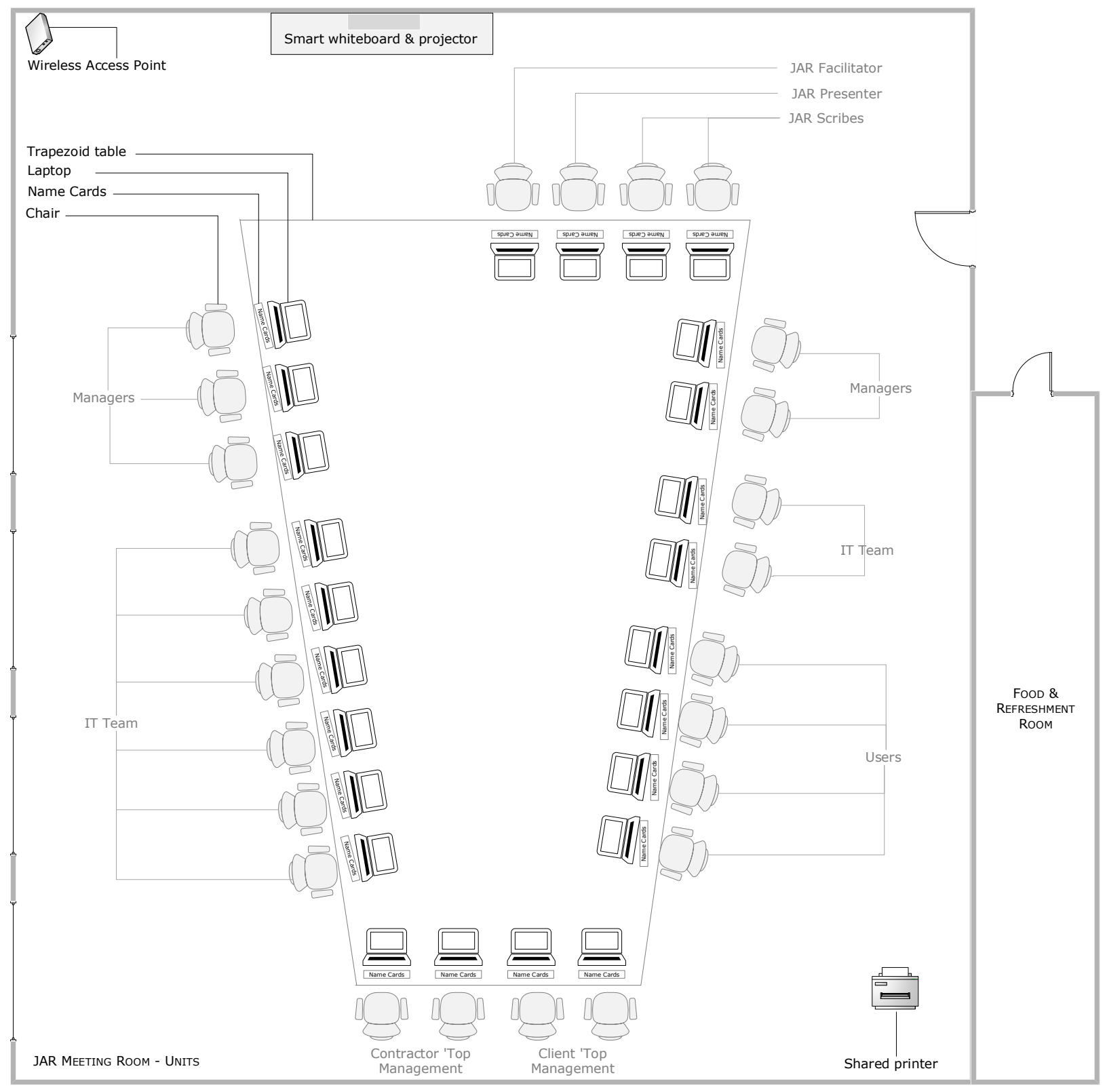

Fig. 1. The Unit JAR Meeting Room Layout. 


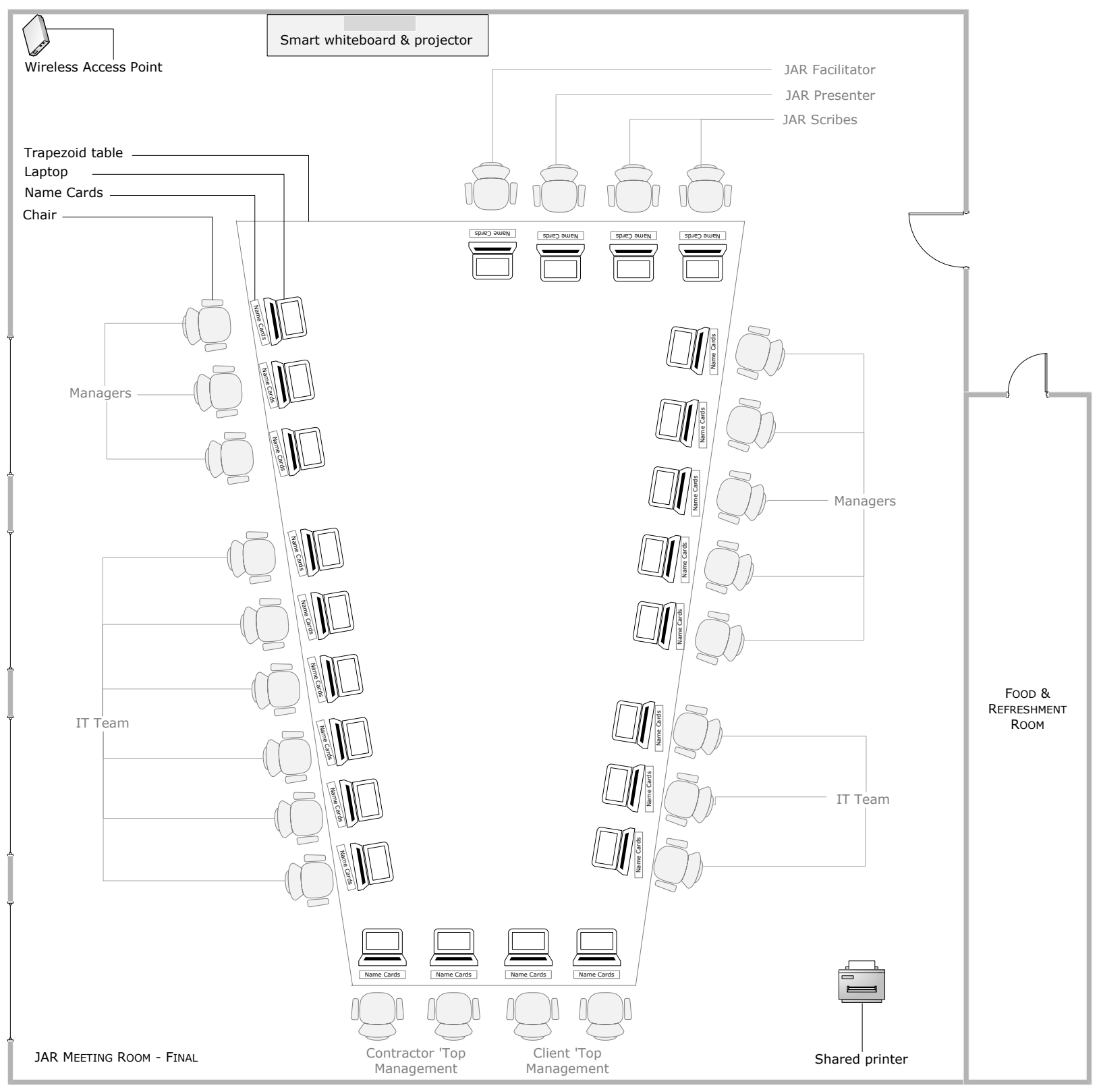

Fig. 2. Final JAR meeting room layout.

Defining the list of the participants with the following information:

- Type of participants - the participants from client side and contractor side.

- Participant unit - the unit which the participant works.

- Participant position - From the client side, shall be selected one person for each position. All participants from the client and contractor side shall be the representative people in their position.

- Participant name and surname.

- Participant email.
- Participant phone number.

Defining the location by finding a place where the JAR meeting shall be conducted. The JAR meeting should be conducted outside of the workplace, while the launch time and the coffee break should be in the same place with JAR meeting but different rooms.

Defining the duration of the JAR meetings by setting date and time: A Unit JAR meeting can be of more than one day depending on the complexity of the information system. Also, the Final JAR meeting can be more than one day per all units; it depends on the complexity of the information system. Both types of JAR meetings, Unit and Final, could have maximum 8 hours meeting per day, including one hour lunchtime and four coffee breaks, five minutes per coffee break. 
Informing the participants by email at least ten days before the JAR meeting: Inform all participants of the JAR meeting and require confirmation from all of them at least five days before the JAR meeting starts. Also, inform that the meeting shall be held only if all invited participants shall confirm JAR meeting. In this information email, should be attached the JAR Meetings Agenda, the materials of the meeting which should be FRs \& NFRs DOC and ICM; In the JAR Meetings Agenda, should be time for Welcome and Remembrance (meeting objectives), Participant's Check-in, Activity based on meeting objectives, lunch time, coffee break time and closure.

\section{The Role of the participants in the JAR meetings:}

The Client participants shall review and approve the functional and non-functional requirements document and the integrated conceptual model during a presentation by JAR Presenter. First, should be reviewed and approve the FRs \& NFRs DOC than the ICM.

The Contractor participants' role is shown in the following:

- The JAR Facilitator - shall open the JAR meetings by explaining the objective of the meeting, present and approve the JAR Meetings Agenda by participants and share the materials of the meeting in the paper if it is necessary otherwise all participants have materials in an email when they are invited for JAR Meetings. The JAR Facilitator also takes care for respecting the agenda by all participants in the JAR meetings and close the meetings. If the JAR meeting is holding for the information system which shall be developed in-house than the JAR Facilitator shall be the system analyst of the institution (JAR Presenter).

- The JAR Presenter (The system analyst) - shall present the prepared functional and non-functional requirements document and the integrated conceptual model of the information system in the JAR meetings. If the JAR meeting is holding for the information system which shall be developed in-house than the JAR Presenter shall be the system analyst of the institution who prepared the requirements document and the graphical representation (FRs \& NFRs DOC and ICM). The JAR Presenter shall also explain what type of source (gathered requirements) is used to prepare the requirements document and the integrated conceptual model. During the gathered requirements, should have in consideration what type of information the guides of this Integrated Framework for Conceptual Modeling require to create a requirements document (FRs \& NFRs DOC) and the graphical representation (ICM) of the information system.

- The other contractor 'IT team, IT Managers and Top Management - shall intervene during the presentation if it is necessary. If the JAR meeting is holding for the information system which shall be developed in-house than the Top Management, IT team and IT Manager shall be in the role of the contractor, whereas the Unit Managers shall be in the role of the client.
- The JAR Scribes - shall make changes in the functional and non-functional document and the integrated conceptual model during the JAR meetings based on the client participants comments, after analyzing them directly in the JAR meeting by the JAR Presenter (the system analyst) and the other IT team members if it is necessary and getting the solution to the client during the JAR meeting, in order all client participants to approve changes directly in the JAR meeting. If the JAR meeting is holding for the information system which shall be developed in-house than the JAR Scriber shall be the system analyst of the institution (JAR Presenter). Also, the JAR Scriber shall be responsible for writing the Minutes of JAR Meetings.

\section{Conducted JAR meetings:}

Initially shall hold the Units JAR meetings, then the Final JAR meeting. The Units JAR meetings shall be held one by one, based on dependency they have in daily work showing which is the first unit that does the job, which is second and so on. Each Unit JAR meeting shall be held in a separate time interval because Top Management, Managers, IT team and IT Managers of the client and the contractor should participate in each unit JAR meeting.

In the Unit JAR meeting shall be reviewed and approved the functional and non-functional requirements document (FRs $\&$ NFRs DOC) and the integrated conceptual model (ICM) by the client participants. During the review process shall be made changes in the FRs \& NFRs DOC and ICM, while the approval shall be made after final changes then sending it to the participants at the end of Unit JAR meeting. After finishing each Unit JAR meeting, the Final JAR meeting with the client and the contractor participants shall be held to make the final review and approval from the client participants.

\section{The Product of the JAR meetings:}

Product of the Unit JAR meetings is the Final version of the functional and non-functional requirements document and the integrated conceptual model of the units which should consider during the Final JAR meeting. During this meeting shall be created also the Minutes of JAR Meeting per each unit with those information's: date, time, main discussions, participants, location, conclusions, and approvals. While, the product of the Final JAR meeting is the Final version of the functional and non-functional requirements document and the integrated conceptual model which should consider during the development of the information system from contractor side. During this meeting shall be created also the Minutes of JAR Meeting per Final JAR meeting with this information's: date, time, main discussions, participants, location, conclusions, and approvals.

\section{A. Joint Approval Requirements Meeting Room Layout}

The JAR Meeting Room Layout presented in Fig. 1 and 2, is used for Unit and Final JAR Meetings and it contains the following components: A trapezoid table and chairs, Laptops for every participant with adequate software's for the JAR meeting (doc software and Microsoft Visio Professional 2016), 
Name cards for every participant, Smart whiteboard and projector in order to create a collaborative environment in JAR meeting, A shared printer in network which is connected to every participant in the JAR meetings, Wireless Access Point.

The arrangement of the trapezoid table based on the JAR Method is presented in the following:

- In the front of the trapezoid table shall be placed, smart whiteboard and projector.

- In the top-left side of the JAR meeting room shall be placed a wireless access point.

- In the bottom-right side of the JAR meeting room shall be placed a shared printer.

- In the beginning part of the trapezoid table shall be placed a laptop for the JAR Facilitator, a laptop for the JAR Presenter (the system analyst) which shall present the Information System based on the functional and non-functional requirements document and the Integrated Conceptual Model, and two laptops for the JAR scribes.

- In the end part of the trapezoid table, in the right side shall be placed two laptops for the client 'Top Management, while in the left side shall be placed two laptops for the contractor `Top Management.

- The right side of the trapezoid table is different for Units JAR meetings and Final JAR meeting: In the right side of the trapezoid table in Units JAR meetings shall be placed laptops for the participants from the client side; near of the top management shall be placed Users than the IT team and in the end the Managers. If the Unit JAR meeting is holding for the information system which shall be developed in-house than in the end part of the trapezoid table shall be placed two laptops for the 'Top Management who shall be in the role of the contractor and client; near of the Top Management shall be the Users than the Unit Managers whereas, the IT Team and IT Managers shall be in the role of the contractor. Whereas, in the right side of the trapezoid table in Final JAR meetings shall be placed laptops for the participants from the client side; near of the top management shall be placed the IT team and IT Managers shall be in the role of the contractor.

- In the left side of the trapezoid table shall be placed laptops for the participants from the contractor side; near of the top management shall be placed IT team than Managers of the IT team.

- Food and Refreshment room shall be near of the JAR meeting room, approximately 5 minutes by foot.

- Both type of JAR meetings shall be hold in same JAR meeting room as it is presented in Fig. 1 and 2 but only participants in the right side of trapezoid table shall be different for those two types of JAR meetings as it is presented.

\section{CONCLUSIONS AND FUTURE WORK}

In this paper is proposed a theoretical method Joint Approval Requirements (JAR), which is for review and approve the system requirements in the JAR meetings with client. This JAR method is ready for scholars to validate during the system analysis and design phase through Mixed Method Case Study by using the Sequential Exploratory Design (QUAL $\rightarrow$ quan) [10], [11]. This design stand for qualitative data collection and analyzing which are followed by the quantitative data collection and analysis with the intention of increasing the findings generalization (Peng, G. C., Nunes, J. M. B., \& Annansingh, F., 2011; Cameron, R., 2009) [11]-[13].

In continues of this study is working on the validation of the JAR method used during the improvement of the eSchedule system at South East European University, In the end of the JAR Meetings shall be conducted the Semi-Structured Interviews with participants to assess their experience related to this method and the Integrated Framework for Conceptual Modeling (IFCMod).

\section{REFERENCES}

[1] Lombriser, Philipp, Fabiano Dalpiaz, Garm Lucassen, and Sjaak Brinkkemper. "Gamified requirements engineering: model and experimentation." In International Working Conference on Requirements Engineering: Foundation for Software Quality, pp. 171187. Springer International Publishing, 2016.

[2] Wagner, Dirk Nicolas. "Breakin'the Project Wave: Understanding and avoiding failure in project management.", 2016.

[3] Bentley, Lonnie D., and Jeffrey L. Whitten. "Systems analysis and design methods". pp. 229-235. Irwin/McGraw Hill, 2007.

[4] Dennis, Alan, Barbara Haley Wixom, and Roberta M. Roth. "Systems analysis and design", pp. 119-143. John wiley \& sons, 2012.

[5] Hyseni, Lindita Nebiu, and Zamir Dika. "Integrated Approach To Conceptual Modeling." International Journal of Advanced Computer Science and Applications 7, No. 12, pp. 213-219. 2016.

[6] Hyseni, Lindita Nebiu, and Zamir Dika, "An integrated framework of conceptual modeling for performance improvement of the information systems" INTECH2017: Seventh International Conference on Innovative Computing Technology, 2017, in press.

[7] Bera, Palash, Anna Krasnoperova, and Yair Wand. "Using ontology languages for conceptual modeling." Cross-Disciplinary Models and Applications of Database Management: Advancing Approaches: Advancing Approaches 1, 2011.

[8] Braga, Bernardo FB, João Paulo Andrade Almeida, Giancarlo Guizzardi, and Alessander B. Benevides. "Transforming OntoUML into Alloy: towards conceptual model validation using a lightweight formal method." Innovations in Systems and Software Engineering 6, No. 1, pp. 55-63. 2011

[9] Mehmood, Kashif, Samira Si-Said Cherfi, and Isabelle Comyn-Wattiau. "CM-Quality: A Pattern-Based Method and Tool for Conceptual Modeling Evaluation and Improvement." In ADBIS, pp. 406-420. 2010.

[10] Morse, Janice M. "Mixed method design: Principles and procedures." Vol. 4. Routledge, 2016.

[11] Aramo-Immonen, Heli. "Mixed methods research design." In World Summit on Knowledge Society, pp. 32-43. Springer, Berlin, Heidelberg, 2011.

[12] Cameron, Roslyn. "A sequential mixed model research design: Design, analytical and display issues." International Journal of Multiple Research Approaches 3 No. 2, pp. 140-152. 2009

[13] Peng, Guo Chao, J. M. B. Nunes, and Fenio Annansingh. "Investigating information systems with mixed-methods research." In Proceedings of the IADIS International Workshop on Information Systems Research Trends, Approaches and Methodologies. Sheffield, 2011. 